\title{
A EDUCAÇÃO INFANTIL SUJEITOS DE DIREITOS
}

\author{
Hingridy Karoliny de Queiroz Arruda ${ }^{1}$ \\ Jaqueline de Moura Santana ${ }^{2}$ \\ Luciana Xavier Cirino ${ }^{3}$ \\ Rejane Aparecida Prado Jesus Lima ${ }^{4}$ \\ Vania Valesca Castilho da Silva Santos ${ }^{5}$
}

RESUMO: O presente artigo objetiva levar os docentes da educação infantil a articular os conteúdos contidos nos diferentes documentos que discutem sobre: "Os direitos das crianças", através de pesquisa e da realização da leitura sistemática e reflexiva sobre o tema, bem como da produção de um texto teórico crítico-reflexivo sobre os direitos das crianças.

Palavras-chave: Docentes. Educação Infantil, Direitos das crianças.

ABSTRACT: This article aims to lead early childhood education teachers to articulate the contents contained in the different documents that discuss: "Children's rights", through research and carrying out a systematic and reflective reading on the subject, as well as the production of a text critical-reflective theorist on children's rights.

Keywords: Faculty. Early Childhood Education, Children's Rights.

\section{INTRODUÇÃO}

Uma forma interessante, para pensar a qualidade no atendimento à criança relaciona-se à ideia de garantia e efetivação de seus direitos, já consagrados universalmente e, do ponto de vista legal, bem definidos.

Esses direitos estão explicitados em documentos que vão desde a Declaração Universal dos Direitos da Criança, para mencionar o plano internacional, passando pela Constituição Federal Brasileira de 1988, Estatuto da Criança e do Adolescente - ECA (lei

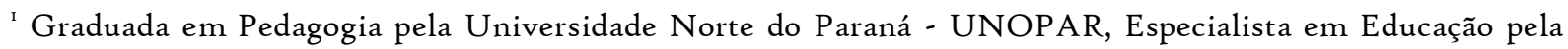
Faculdade Afirmativo

${ }^{2}$ Graduada em Pedagogia pela Universidade Norte do Paraná - UNOPAR.

${ }^{3}$ Formação Ensino Técnico Magistério pelo Instituto de Educação Carlos Pasquale.

${ }^{4}$ Graduada em Pedagogia pela Unopar - Universidade Norte do Paraná, Especialista em Educação Infantil: Concepção de Infância e Trabalho Educativo com Ênfase em Alfabetização e Letramento pela Faculdade Afirmativo.

${ }^{5}$ Graduada em Pedagogia pela Faculdade INVEST de Ciências e Tecnologias, Especialista em Educação Infantil pelo IESMIG - Instituto de Ensino Superior de Minas Gerais.
} 
n. 8.069 de 1990), Lei de Diretrizes e Bases da Educação Nacional - LDB (n. 9.394/96), e o Referencial Curricular Nacional para a Educação Infantil, de 1998, entre outros.

Quanto à questão educacional, o aspecto mais relevante da Constituição Federal de 1988 para a educação infantil está em seu art. 208, inciso IV, ao afirmar que "o dever do Estado com a educação será efetivado mediante a garantia de: (...) atendimento em creche e pré-escola às crianças de zero a seis anos de idade”. Além de outros tópicos importantes no que diz respeito ao atendimento de o a 6 anos na lei maior do país, interessa destacarmos, do seu art. 206, no qual se afirmam os princípios sob os quais o ensino deve ser ministrado, o contido no inciso VII - "garantia de padrão de qualidade" como um dos norteadores também para as instituições de educação infantil.

Com base nesses dois artigos, podemos concluir que, no plano legal, a oferta de educação infantil não apenas passa a ser uma obrigação do Estado como também deve ser oferecida com qualidade.

\section{DESENVOLVIMENTO}

O Estatuto da Criança e do Adolescente define os seguintes direitos como fundamentais: direito à vida e à saúde (cap. I), à liberdade, ao respeito e à dignidade (cap. II), à convivência familiar e comunitária, à educação, à cultura, ao esporte e ao lazer (cap. III). Quanto à educação, o direito é previsto para todas as faixas etárias, incluindo a criança de o a 6 anos de idade. Para o que nos interessa mais imediatamente na discussão acerca de qualidade na educação infantil, destaquemos dois importantes aspectos contidos no ECA.

No art. $5^{\circ}$ afirma-se que "nenhuma criança ou adolescente será objeto de qualquer forma de negligência, discriminação, exploração, violência, crueldade e opressão, punido na forma da lei qualquer atentado, por ação ou omissão, aos seus direitos fundamentais.” No art. 53, ao tratar do direito à educação, define que esta deve assegurar, entre outros aspectos: “o direito de ser respeitado por seus educadores.” Para a educação infantil especialmente, em face das limitações de autodefesa das crianças em razão de sua pouca idade, isto é absolutamente relevante. Sabe-se que em algumas instituições, práticas como os castigos de toda natureza, algumas vezes físicos, ainda se fazem presentes.

O fato de haver uma lei contra isso não garante, evidentemente, a sua superação, mas representa, sem dúvida, um poderoso instrumento de repressão a essas 
práticas. Ademais, de uma outra forma, o conteúdo desses artigos reafirma a Constituição, indicando ser possível acionar o Estado para que ele não apenas cumpra seu dever de oferecer o atendimento a todos que assim o queiram mas, além disso, que o faça baseado no respeito aos direitos das crianças, ou seja, com qualidade.

A nova Lei de Diretrizes e Bases da Educação Nacional, de 1996, além de ratificar o contido na Constituição e no ECA quanto à obrigatoriedade de oferecimento de educação infantil em creches e pré-escolas por parte do Estado (art. 4 o, inc. IV), em seu art. 29 define como finalidade da educação infantil "o desenvolvimento integral da criança até 6 anos de idade, em seus aspectos físico, psicológico, intelectual e social, complementando a ação da família e da comunidade." Além disso, afirma que a avaliação nessa etapa da educação "far-se-á mediante acompanhamento e registro de seu desenvolvimento, sem o objetivo de promoção, mesmo para o acesso ao ensino fundamental." Pelo que se tem, embora não se explicite especificamente a temática da qualidade para a educação infantil, o seu conteúdo demonstra preocupação com a questão ao propor como objetivo o desenvolvimento integral da criança e uma avaliação de caráter mais qualitativo.

O Referencial Curricular Nacional para a Educação Infantil explicita os seguintes princípios sobre o que seria um trabalho de qualidade: - respeito à dignidade e aos direitos das crianças, consideradas nas suas diferenças individuais, sociais, econômicas, culturais, étnicas, religiosas etc.; • direito das crianças a brincar, como forma particular de expressão, pensamento, interação e comunicação infantil; • acesso das crianças aos bens socioculturais disponíveis, ampliando o desenvolvimento das capacidades relativas à expressão, à comunicação, à interação social, ao pensamento, à ética e à estética; • a socialização das crianças por meio de sua participação e inserção nas mais diversificadas práticas sociais, sem discriminação de espécie alguma; • atendimento aos cuidados essenciais associados à sobrevivência e ao desenvolvimento de sua identidade de maneira ampliada nesse documento. Tal ampliação no entendimento de quais são os direitos da criança pequena traduz, em certa medida, os resultados de uma longa trajetória de discussão e estudos acerca da especificidade da faixa etária e dos significados que uma educação formal, fora do ambiente familiar, pode adquirir nessa fase da vida.

No que se refere às políticas de educação infantil, são alguns dos próprios direitos das crianças já consolidados: o direito à brincadeira, à atenção individualizada, a 
um ambiente aconchegante, seguro e estimulante, ao contato com a natureza, à higiene e à saúde, a uma alimentação sadia, a desenvolver a criatividade, imaginação e capacidade de expressão, ao movimento em espaços amplos, à proteção, ao afeto e à amizade, a expressar seus sentimentos, a uma especial atenção durante o período de adaptação, a desenvolver sua identidade cultural, racial e religiosa.

Como se pode perceber, a idéia de direitos tem sido abordada e difundida, estando presente em diferentes leis e documentos oficiais.

A questão do atendimento na educação infantil é polêmica, concorda-se. Por um lado, porque não se tem clareza quanto à real demanda existente e, por outro, porque a matrícula por parte das famílias não é obrigatória, ainda que, do ponto de vista legal, seja dever do Estado oferecê-la. Como não se conhece com clareza a demanda existente, ou seja, quantas famílias querem colocar seus filhos numa instituição de educação infantil, não sendo a matrícula uma obrigatoriedade, torna-se muito mais difícil exigir do Estado o seu referido "dever" de oferecimento de vagas a todos que assim o quiserem.

Suas considerações são importantes na medida em que denunciam o reiterado desrespeito com que as políticas de educação infantil têm sido implementadas no Brasil. De fato, a tradição da maioria das creches e pré-escolas para a população de mais baixa renda é marcada por um atendimento "pobre".

Tais constatações, contudo, não podem servir como fundamento para a recusa de discutir e, consequentemente, de lutar pela expansão na oferta de vagas. Primeiro, porque estamos partindo do princípio de que a educação infantil é direito de toda criança, etapa fundamental para o seu pleno desenvolvimento.

Assim, não só a defesa da ampliação de vagas é necessária mas, também, a possibilidade de períodos de atendimento que sejam mais compatíveis com as necessidades de cada família.

Se é evidente que algo precisa ser feito por um atendimento que respeite a criança, garantindo-lhe as melhores condições, é preciso que tal atendimento efetivamente exista para todas as crianças/famílias que dele se queiram valer. Se o debate ficar centrado na questão da qualidade como algo isolado, corre-se o risco de se reafirmarem as políticas vigentes e o seu caráter marcado pela exclusão, pois, em vez de centros de excelência para alguns privilegiados, precisamos de boas escolas para todos. 
Como se sabe, as condições de infra-estrutura e a formação dos profissionais que trabalham com educação infantil, especialmente em creches, são bastante precárias se olharmos para o país como um todo.

Em termos de recomendação pode-se dizer, por um lado, que o entendimento da necessidade de agrupamentos pequenos quando se trata da educação infantil não é algo novo, já havendo um generalizado consenso a esse respeito e, por outro, que os documentos oficiais fazem indicações que poderíamos considerar bem razoáveis.

Ocorre que, como já mencionado, as atuais políticas educacionais, especialmente as de âmbito nacional, parecem primar pela retórica. Primeiro porque não há lei, norma, regulamentação ou exigência quando se trata dessa relação, mas, apenas sugestão ou indicação. Isto porque, se já temos uma séria defasagem no atendimento à demanda, superlotando as escolas existentes com um número elevadíssimo de crianças, imagine-se o que ocorreria caso se tivesse que seguir com rigor essas orientações.

Assim, embora se possa considerar um avanço o fato de haver orientações oficiais, estabelecendo-se como um dos critérios de qualidade uma razão adulto/criança que privilegie pequenos agrupamentos, as condições objetivas não são oferecidas, porque não há políticas de financiamento para a educação infantil.

Em se tratando de crianças pequenas, cujas necessidades de educação e cuidado podem e devem ser entendidas de modo mais abrangente, o problema do excesso de alunos por professora parece tornar se ainda mais sério.

Todas as crianças sejam ouvidas e respeitadas em todos os seus direitos, relaciona-se também com as próprias condições de trabalho a que são submetidos os profissionais que atuam na área, especialmente as professoras. Embora muitos estudos tenham-se realizado e a idéia da necessária formação específica já esteja bastante difundida, estando contemplada na nova LDB em seu art. 62, há ainda muito que fazer para que se supere um antigo e arraigado entendimento de que para trabalhar com educação infantil basta ser paciente, “criativo” e gostar de crianças.

Portanto, faz-se necessário reforçar que uma escola de qualidade precisa contar com profissionais especialmente preparados, tanto para as questões relativas à aprendizagem e ao desenvolvimento infantil como um todo, quanto para questões mais amplas que envolvam conhecimentos sociológicos, filosóficos, históricos e políticos, até 
para que esses profissionais consigam apreender de modo mais crítico as condições de trabalho a que são submetidos e as suas conseqüências, para si e para as crianças.

No caso da educação infantil, faltam especialmente políticas de financiamento para que se amplie, quantitativa e qualitativamente, a oferta de creches e pré-escolas. O terceiro e último aspecto a que nos propusemos discutir neste artigo diz respeito às relações que se dão no interior das instituições educacionais, especialmente na pré-escola. Como tomamos o eixo dos direitos como fundamento para discutir qualidade, não bastaria problematizar e afirmar a necessidade de ampliação da oferta de vagas com uma razão adulto/criança mais adequada.

Estas seriam condições para se garantir minimamente alguns dos direitos das crianças, tais como o próprio acesso à educação infantil, bem como o direito a uma atenção mais individualizada, a um ambiente mais seguro e quiçá mais aconchegante e estimulante, à higiene e à saúde, por exemplo. Entretanto, é necessário também refletir sobre a dinâmica que ocorre na própria unidade educacional para se abarcar direitos tais como os de proteção, afeto e amizade, a expressão dos próprios sentimentos, o desenvolvimento da criatividade e da imaginação por parte da criança.

Um outro modelo de atendimento e as creches, como também as pré-escolas e mesmo as escolas primárias passam a sofrer sérias críticas por prestarem serviços tidos como assistenciais (cuidados com alimentação e saúde) em detrimento do educacional. Dessa crítica parece surgir uma espécie de consenso de que assistência é o oposto de educação, sem se ponderar sobre a possibilidade de que ambas pudessem se coadunar em benefício das crianças.

Assim, é nesse quadro que começa a ganhar força a idéia de que se até então as creches, em especial, tinham sido equipamentos de mera assistência, era chegado o momento de fortalecer um modelo "educacional". O movimento, aliado principalmente ao fato de que a educação infantil, especialmente a creche, ficou por muito tempo longe dos currículos dos cursos de pedagogia e, como tema de pesquisas, foi relegada a segundo plano, repercute ainda hoje, permanecendo a idéia de que a precariedade no atendimento oferecido pelas instituições de educação infantil deve-se à sua história.

Analisar as instituições por esta ótica poderia apenas encobrir a forma sob a qual, historicamente, o atendimento tem sido ministrado às crianças de diferentes níveis socioeconômicos. 
Todo esse processo parece ter gerado uma incompreensão acerca da dimensão e do significado do termo educação nas instituições de educação infantil e provocado uma visão negativa sobre tudo aquilo que se relaciona ao cuidado, como se este fosse sempre e necessariamente a expressão de práticas assistencialistas.

Essa perspectiva, à medida que se mostra mais abrangente e se refere a necessidades e direitos de toda e qualquer criança, pode auxiliar na superação da idéia ainda vigente de que, para um segmento social e etário caberia o "cuidado", entendido apenas como "assistencialismo" e, no outro extremo, para o outro segmento caberia um trabalho "pedagógico", este também entendido de forma limitada porque ignorando outras necessidades e direitos.

Se por um lado o cuidado é algo fortemente presente, por outro, ele é ora negado, porque tido como antiprofissional, ora visto como algo característico ou mesmo inerente à condição feminina, materna; assim, em ambos os casos, o cuidado é compreendido não como uma característica ou atributo profissional típico daqueles que trabalham com crianças, mas, antes, como característica doméstica,

Assim, tomar a criança como ponto de partida exigiria compreender que para ela, conhecer o mundo envolve o afeto, o prazer e o desprazer, a fantasia, o brincar e o movimento, a poesia, as ciências, as artes plásticas e dramáticas, a linguagem, a música e a matemática.

Assim, além do exemplo mencionado, é muito comum observar professoras queixando se de não terem tido um bom dia de trabalho porque, em razão de estarem cansadas, por exemplo, "apenas" deixaram as crianças brincarem, ou "apenas” contaram uma história etc. Também é comum observar professoras que, após a realização de um jogo ou brincadeira muito rica em possibilidades de reflexão para as crianças, sentem-se na obrigação de "sistematizar" a aprendizagem e, então, "completam" a atividade oferecendo folhas com exercícios que, em geral, servem apenas para treinar a motricidade e aquietar a meninada.

\section{CONCLUSÃO}

Diversas são as possibilidades para se discutir, avaliar ou propor padrões de qualidade na educação infantil. O que se pode concluir, entretanto, com base na discussão sistematizada neste artigo, é que muito se tem a fazer para que a escola pública de educação 
infantil ou a pré-escola, porque dela tratamos com maior ênfase ofereça melhores condições de atendimento.

Há escolas e profissionais muito empenhados, criando alternativas interessantes de trabalho, a despeito da falta de investimento estatal e de toda sorte de dificuldades. Todavia, ainda que o compromisso profissional de cada educadora(or) seja de fundamental importância, É preciso insistir que ganhos qualitativos devem ocorrer de maneira generalizada e, para tanto, as ações - movimentos, reivindicações - devem ter um caráter mais coletivo.

Finalmente, vale dizer que o coletivo pode ser entendido como um corpo formado também pela sociedade civil, em especial pelas mães (famílias) das crianças. A história já mostrou que sua participação é decisiva na conquista de direitos educacionais.

\section{REFERÊNCIAS}

BRASIL. Constituição da República Federativa do Brasil. Brasília, DF: Senado, 1988.

Estatuto da criança e do adolescente, Lei ${ }^{\circ}$ 8.069, de 13 de julho de 1990. Brasília, DF, Diário Oficial da União, i6 jul. 1990.

Diretrizes e Bases da Educação Nacional. Lei no 9.394/1996, de 20 de dezembro de 1996. Estabelece as diretrizes e bases da educação nacional. Brasília, DF, Diário Oficial da União, 23 dez. 1996. 